FACULDADE DE LETRAS

INSTITUTO DE ARQUEOLOGIA

FOSÉ D'ENCARNACAO

\title{
ESTELAS ROMANAS INÉDITAS \\ DO SUDOESTE ALENTEJANO
}


José D'Encarnaçĩo

Assistente da Faculdade de Letras de Coimbra

ESTELAS ROMANAS INÉDITAS DO SUDOESTE ALENTEJANO

"Conimbriga" (Coimbra), XVII, 1978, p. 41-53

Resumo: Publicam-se oito estelas encontradas em diversos lugares do Baixo-Alentejo, todas inéditas, com excepção da n. ${ }^{\circ} 6$. Trata-se de um grupo homogéneo: mesma utilização de xistos locais, mesmo tipo formal, seguindo uma tradição que remonta à Idade do Bronze, mesma concisão dos textos, que não invocam os deuses manes e omitem frequentemente outras fórmulas funerárias, mesma onomástica indigena recentemente adaptada à onomástica latina, denunciando uma população que acaba de sentir os efeitos da romanização.

Résumé: Huit stèles funéraires trouvées dans la zone méridionale de la province d'Alentejo (Portugal) sont ici publiées par la première fois (seule la $n .^{\circ} 6$ était déjà connue). Il s'agit d'un groupe homogène: même utilisation des xistes locaux, mème format général (qui remonte à l'âge du Bronze final de la région), même concision des textes, qui ne font pas invocation des dieux mânes et même onomastique indigène récemment adaptée à l'onomastique latine, denonçant par là une population qui vient d'être romanisée. 


\section{ESTELAS ROMANAS INÉDITAS DO SUDOESTE ALENTEJANO}

Possui o P.e António Serralheiro, prior de Messejana, uma colecção de estelas funerárias que, mercê do seu grande interesse pelas coisas do passado, tem procurado cuidadosamente preservar, ao longo de muitos anos. Aliás, ao P.e Serralheiro está a Arqueologia a dever os mais relevantes serviços na protecção dos vestígios pré-históricos e romanos da região onde a sua acção pastoral se exerce. Sempre solícito, o prior de Messejana informou-nos do local de achado das estelas, possibilitou-nos amavelmente o estudo das peças, não se poupando a esforços nesse sentido. Para ele o nosso "muito obrigado".

Das sete estelas, apenas a n. ${ }^{0} 6$ já foi referenciada, sem que, porém, o seu estudo tivesse sido efectuado; as outras estão inéditas. Ajuntámos uma oitava (a n. ${ }^{\circ} 2$ ), recentemente descoberta e guardada na Câmara Municipal de Ourique $\left.{ }^{(}{ }^{1}\right)$.

Trata-se dum conjunto passível de facultar o esboço das características individualizantes da epigrafia do que, grosso modo, podemos chamar o Sudoeste Alentejano (Conventus Pacensis, Lusitania). A tipologia dos monumentos recorda as estelas da Idade do Bronze aí também encontradas (numa sequência cultural que reputamos de interesse); o formulário, extremamente simples, remonta, em nosso entender, aos primórdios da romanização $\left({ }^{2}\right)$, altura em que as minas de Aljustrel teriam começado a ser exploradas.

(1) Ao Sr. Presidente do municipio ouriquense, Ramiro Sobral, agradecemos as facilidades concedidas para o estudo do monumento, que se encontra arrecadado na garagem da Câmara, juntamente com outros materiais destinados ao futuro museu municipal.

$\left({ }^{2}\right)$ Outros textos já foram publicados, da mesma região, com idênticas características tipológicas e formais. Cfr. CIL II 76 e 98; «O Archeologo Português» $(=A P)$ XIII, 1908 p. 283-4, e III série, III, 1969 p. 299. 
Este estudo preliminar, destinado quase exclusivamente a dar a conhecer a existência dos monumentos, será posteriormente ampliado e integrado no catálogo epigráfico do Conventus Pacensis, não podendo ser desligado do ambiente mineiro em que surge: hão-de ter-se em conta os textos epigráficos $\left(^{3}\right)$ e o contexto arqueológico $\left({ }^{4}\right)$.

\section{$1-$ Foto 1}

Estela funerária de ardósia $\left.{ }^{5}\right)$, amarelada, encontrada no Monte da Vinha Grande, freguesia de Messejana, concelho de Aljustrel. Bordos laterais talhados a direito, arredondada superiormente, apenas desbastada em baixo na parte a enterrar. Líquenes abundantes dificultam a leitura - a fotografia e o decalque pouco adiantam. Entendemos todavia útil publicar a fotografia da lápide, que permite ao menos julgar da sua forma. Campo epigráfico rebaixado, limitado, na altura, por um sulco horizontal.

Dimensões $\left({ }^{6}\right): 100 \times 50,5 \times 9,5$. Campo epigráfico: $26,5 \times$ $\times 50,5$.

\section{C(aius $) \cdot$ ANVIVS / CFBVANVS / $\mathrm{H}($ ic $) \cdot \mathrm{S}($ itus $) \cdot \mathrm{E}($ st $)$}

Aqui jaz Gaio Ânvio (?)...

Altura das letras: 5. Espaços: $1: 5 ; 2: 1,5 ; 3: 4,5 ; 4: 0$. Inédita.

$\left(^{3}\right)$ Entre outros, as tábuas de bronze (Álvaro D'Ons, Epigrafia juridica de la España Romana, Madrid, 1953, p. 71-133; AP, III série, IV, 1970 p. 125-163) e a homenagem ao procurador das minas ( $A P$, III série, I, 1967 p. 130-131).

(4) Ver Alarcão (Jorge), Portugal Romano, 1974, p. 125-129 e 217 (bibliografia).

${ }^{(5)}$ Não nos foi possível fazer examinar as peças por um geólogo; por isso, uma posterior análise cientifica do material possibilitará a sua determinação mais exacta.

$\left.{ }^{6}\right)$ Máximas, em centímetros, e nesta ordem: altura $\times$ largura $\times$ espessura. 
Paginação verosimilmente segundo um eixo de simetria. Caracteres de ductus irregular, embora no geral ligeiramente inclinados para a direita. Pontos circulares.

$\mathrm{Na}$ l. 1, após o $\mathrm{N}$, parece haver $\mathrm{V}$; entre o $\mathrm{V}$ e o $\mathrm{S}$, bastante espaço. Tanto Anvius como Anuivs surgiriam aqui pela primeira vez - ao que supomos - na epigrafia romana; será Annius $\left({ }^{7}\right)$ mal gravado?

Na l. 2, estará o cognomen, se tivermos em conta a estrutura habitual da epigrafia do SW. A indicação de filiação - C(aii) $\mathrm{F}($ ilius $)$ - ou de estatuto - $\mathrm{C}($ aii) $\mathrm{L}($ ibertus $)$ - seguida da idade - $\mathrm{AN}($ norum $) \mathrm{V}$ - parece-nos hipótese a rejeitar.

Estamos possivelmente em presença dum indígena que adoptou os tria nomina.

A ausência de invocação aos Manes, a simplicidade do formulário, o uso do nominativo apontam para os começos do Império.

\section{$2-$ Foto 2}

Estela funerária de xisto, castanho-clara, encontrada no Monte Valadão, Conceição, Ourique, em Abril de 1977. Praticamente intacta: pequenas falhas em cima, atingindo uma o A da l. 1, e em baixo à direita. Cobria uma sepultura de inumação, donde foi retirado o esqueleto. Campo epigráfico rebaixado e polido. Linhas auxiliares duplas, bem visíveis.

Dimensões: $106 \times 57 \times 14$. Campo epigráfico: $31,5 \times 57$.

\section{IVLIA / SEILI·F(ilia) / AMOENA}

Júlia Amena, filha de Seilo.

Alt. das letras: $8(\mathrm{~S}=7,3,0=7,5)$. Espaços: $1: 2,5$; $2: 1,5 ; 3: 1,5 ; 4: 2,5$.

Inédita.

${ }^{7}$ ) Alguns exemplos registados no conventus Pacensis: CIL II 3, 13, 948 e 5176; ILER 3692; SANTOS (M. Luísa E. V. A.), Arqueologia Romana do Algarve, I, 1971, p. 173-175. CIL II 948 é a mesma inscriçãa que Abel Viana estudou no "Arquivo de Beja», III, 1946, p. 24-25, fig. 16; provém, por conseguinte, de Cuba e ainda hoje existe na ponte de Vila Ruiva. 
Paginação muito cuidada, segundo um eixo de simetria rigoroso. Caracteres em capital quadrada, extraordinariamente bem gravados, elegantes, do começo do Império. Ponto em forma de triângulo isósceles, com vértice para cima.

Iulia Amoena, nome outras vezes documentado no Conventus Pacensis $\left({ }^{8}\right)$, é filha dum indigena, aqui designado por um cognomen de provável origem céltica pela primeira vez registado. Efectivamente, não consta na obra de Kajanto $\left({ }^{9}\right)$, nos índices do CIL VI (Roma) ou no trabalho de Schulze $\left({ }^{(10}\right)$; segundo Holder $\left({ }^{11}\right)$, a raiz $\mathrm{Sei}$ - ou Sel - é provavelmente céltica, citando (p. 1459) Seilenses (CIL II $2562=$ ILER 5453) e Seiliensis (AP XIX 1914 p. $365=$ = ILER 5410). Parece-nos este antropónimo relacionável com outros claramente indígenas peninsulares: Saelcus (ILER 2554, ILER $937=$ HAE 1022) $\left({ }^{12}\right)$, Saelgus $\left({ }^{13}\right)$ ou mesmo Sailgius $\left({ }^{(4)}\right)$.

O uso do gentilício Iulia (abundante na região), acompanhado dum cognome tão frequente e o carácter indigena de Seilus, provado pela onomástica, levam-nos a pensar que estamos perante indivíduos romanos de fresca data.

Aliás, a paleografia e a simplicidade do texto (sem qualquer fórmula votiva ou funerária) situam o monumento na primeira metade do séc. I.

(8) ILER 6186, CIL II 156. É muito frequente na Peninsula a junção destes dois antropónimos.

(9) Kajanto (Iiro), The Latin Cognomina, Helsínquia, 1965.

$\left.{ }^{10}\right)$ Schulze (Wilhelm), Zur Geschichte Lateinischer Eigennamen, Berlim, 1966.

(11) Holder (A.), Altkeltischer Sprachshatz, Graz, 1961-62 (reimpressão).

(12) $\mathrm{HAE}=$ Hispania Antiqua Epigraphica, suplemento do "Archivo Español de Arqueologian, Madrid.

(13) Numa inscrição inédita da região de Badajoz, em granito, datável do séc. I: CAMIRA / SAELGI / F. H. S. E. Foi-nos amavelmente comunicada por Jean-Pierre Bost e Anne-Marie Demailly, do Centre Pierre Paris. Agradecemos, aliás, a Mlle. Demailly a colaboração que nos prestou, nomeadamente as informações aqui exaradas a propósito deste antropónimo.

(14) ILER $6358=$ HAE 217. 


\section{$3-$ Foto 3}

Estela funerária de ardósia, encontrada no Monte do Reguengo, Messejana, Aljustrel. Deve ter tido posterior utilização, de sorte que da placa inicial, rectangular, resta uma porção no sentido da diagonal partindo do canto superior esquerdo, onde foi aberto um orifício e traçada uma Jinha oblíqua. Como há vestígios das quatro beiras, é possivel determinar quais teriam sido as dimensões totais. De resto, o texto só foi afectado no lado esquerdo, pondo problemas de reconstituição da l. 1. Campo epigráfico não distinto. Utilizadas linhas auxiliares.

Dimensões: $54 \times 46 \times 2$.

[BO ?]VTA-IVLIAE (?) $\mathrm{F}($ ilia $) / \mathrm{AN}($ norum) $\cdot \mathrm{XV}$ (quindecim)./ / $[\mathrm{H}(i c) \cdot \mathrm{S}(i t a)] \cdot \mathrm{E}(s t) \cdot \mathrm{S}(i t) \cdot \mathrm{T}(i b i) \cdot \mathrm{T}($ erra $) \cdot \mathrm{L}($ evis $)$

Aqui jaz Bouta (?), filha de Júlia, de quinze anos. Que a terra te seja leve

Alt. das letras: 1.1 e $2: 5,3 ; 1.3: \mathrm{E}=6,3, \mathrm{~S}=5,3, \mathrm{~T}=6$, $\mathrm{L}=5,7$. Espaços: 1: 27; 2: 0,5; 3: 0,3/1, 3; 4: 10 (aprox.).

Inédita.

Paginação provavelmente alinhada à esquerda, se atendermos ao alinhamento desse bordo em cima. Caracteres capitais, na perpendicular, esguios, barras horizontais curtas, bem gravadas a escopro e não em bisel. Pontos profundos, circulares, obtidos com instrumento perfurante.

$\mathrm{Na}$ l. 1, ao antropónimo inicial deve faltar uma ou, no máximo, duas letras. Bouta (= Boutia?), cognome indígena registado na Península $\left({ }^{15}\right)$, seria possível. Considerando que o resto de haste vertical no fim da linha será de um F (a falha teria ocorrido ao nível da barra do meio), teríamos de ver na pedra o nexo AE;

$\left({ }^{15}\right)$ Cfr. Untermann (J), Elementos de un Atlas antroponimico de la Hispania Antigua, Madrid 1965, p. 72-73, mapa n. ${ }^{\circ} 18$. 
apesar de a falha se ter aproximado da haste direita do $\mathrm{A}$, não nos parece que o E tenha existido. Lapso do lapicida? Ou haverá outra interpretação para a 1. 1?

A estar certa a nossa hipótese, a jovem poderia ser uma filha natural, pois era o nome da mãe o indicado. Tendo sido inscrita na gens Iulia, aquando do seu contacto com as estruturas romanas, continuaria a designar a filha unicamente pelo nome indigena.

Embora mais tardio que os anteriores, o epitáfio situa-se também no séc. I: pela paleografia, ausência de invocação aos Manes e simplicidade do formulário.

\section{$4-$ Foto 4}

Estela funerária de grauvaque, cinzento-amarelada, encontrada na propriedade designada Barrada, Messejana, Aljustrel. Bordos talhados, campo epigráfico rebaixado em relação ao resto da superfície, rudemente afeiçoada.

Dimensões: $101 \times 47 \times 16$. Campo epigráfico: $26,5 \times 37,5$.

LABERIA / M $($ arci $) \cdot \mathrm{F}($ ilia $) \cdot$ COIMIA

Labéria Coimia, filha de Marcos.

Alt. das letras: 1. $1: 7 ; 1.2: 6,5$. Espaços: 1. $4 ; 2: 1 ; 3: 6,5$.

Inédita.

Embora o texto pareça centrado no campo epigráfico, a paginação não é primorosa: as palavras descaem da esquerda para a direita. Caracteres actuários, de largura irregular, pouco profundos: $\mathrm{B}$ assimétrico, $\mathrm{M}$ bastante largo, $\mathrm{C}$ esguio, $\mathrm{O}$ oval. Pontos circulares.

O gentilício Laberia é frequente no Conventus Pacensis. Coimia será uma forma equivalente ao cognome Coemea, registado outras vezes na Península mormente em Lara de los Infantes (16)

(16) CIL II 2788, 2866 e 2867. Ver também Aв ́́solo (José A.), Epigrafia Romana de la Región de Lara de los Infantes, Burgos, 1974, inscriçōes n. ${ }^{\circ} 45$, 
e que, segundo Holder $\left({ }^{17}\right)$, tem como radical o vocábulo celta * coimos, querido. Teríamos, assim, de novo, um vestígio muito concreto de aculturação antroponímica - uma população indígena que adopta os usos onomásticos latinos do invasor (note-se, por exemplo, a filiação bem indicada), mantendo, no entanto, cognomes tradicionais. Coimia é, pois, um hapax e, se aceitarmos a hipótese semântica de Holder, aquela forma que foneticamente mais se aproxima do radical.

A simplicidade do formulário leva-nos a colocar o monumento nos primeiros tempos do Império.

\section{$5-$ Foto 5}

Estela de grauvaque, acinzentada, partida em cinco pedaços ajustáveis. O desgaste nas zonas de fractura impede uma leitura fácil.

Dimensões: $94 \times 50 \times 11$

$\mathrm{L}($ ucius $) \cdot \mathrm{LO}[\ldots] \mathrm{CIS} / \mathrm{ICV}[\ldots] \mathrm{MAX} / \mathrm{VM}[\mathrm{V}] \mathrm{S} \cdot \mathrm{AN}($ norum $)$ / XXXV (triginta quinque $) \cdot \dot{\mathrm{H}}($ ic $) \cdot \mathrm{S}($ itus $) \cdot \mathrm{E}(s t) \cdot($ sit $) \mathrm{T}($ ibi $) \cdot \mathrm{T}($ erra $)$ $\mathrm{L}$ (evis)

Aqui jaz Lúcio Lo(...)cisico(...) Máxumo, de trinta e cinco anos. Que a terra te seja leve.

Alt. das letras: 1. $1: 6,5 ; 1.2: 5 ; 1.3: 6 ; 1.4: 6(\mathrm{~S}=5)$. Espaços: 1: 19;2: 2,5;3:2; 4: 1; 5: 49 .

Inédita.

É provisória a leitura do nomen: apesar de termos apresentado o que nos parece ver na pedra, a falta de paralelos e a aparente terminação em -icus, quando seria de esperar algo como - icius

$84,158,170,173,183$. Outros achados e comentários foram publicados por Albertos (M.a Lourdes), La Onomastica Personal Primitiva de Hispania Tarraconense y Betica, Salamanca 1966, p. 92, e "Emerita", XXXII, 1964, p. 241 e XL 1972 p. 28.

(17) O. C., I, col. 1661, s. v. "Coem-ea". 
- levam-nos à dúvida, tanto mais que a epígrafe se encontra muito desgastada a esse nível.

$\mathrm{Na}$ 1. 2, o A não tem travessão. Na l. 3, o segundo $\mathrm{V}$ desapareceu na fractura, que, aliás, também fez sumir um pouco o S. Na l. 4, cremos que a falha levou o L, cuja haste vertical mal se deixa perceber - por lapso ou falta de espaço foi omitido $\mathrm{S}(i t)$. Aliás, no n. ${ }^{\circ} 6$ encontraremos também uma fórmula incompleta.

Caracteres actuários, desajeitadamente gravados. Alinhamento à esquerda e possivelmente também à direita.

O cognome latino Maxumus é frequente no conventus Pacensis com esta grafia $\left({ }^{18}\right)$. Estamos eventualmente perante um indígena romanizado, como o indica a existência dos tria nomina.

A ausência de invocação aos Manes, o uso do nominativo e a simplicidade do texto induzem-nos a colocá-lo no séc. I da nossa era.

\section{$6-$ Foto 6}

Estela funerária de grauvaque, castanho-amarelada, encontrada no sítio de Carvalho, Vale de Santiago, Odemira. Rudemente afeiçoada, apresenta inferiormente, à direita, pequenas cavidades dispostas irregularmente. Campo epigráfico alisado, rebaixado; linhas auxiliares duplas e paralelas limitam superior e inferiormente a l. 1, mal se notando sob a l. 2. Um sulco oblíquo, feito decerto na altura do achamento, atingiu as três primeiras letras; também o início da I. 2 foi atingido.

Dimensões: $108 \times 42 \times 12$. Campo epigráfico: $31 / 34 \times 42$.

CN(aei) NAEIDI / RVFI. [S(it)]. T(erra) $\mathrm{L}($ evis $)$

De Gneu Nêidio Rufo. Que a terra (te) seja leve.

Alt. das letras: 1. $1: 7,3 ; 1.2: 7,3(\mathrm{I}=6,7 ; \mathrm{T}=7)$. Espaços: entre as 1 . auxiliales: 1,$5 ; 1: 0,7 ; 2: 3 ; 3: 11 / 15$.

(18) Mais sete exemplos. 
Viana (Abel), Ferreira (O. Veiga) e Serralheiro (P.e A.), Apontamentos arqueológicos dos concelhos de Aljustrel e Almodôvar, separ. de «Publicações do XXIII Congresso Luso-Espanhol para o Progresso das Ciências», VIII, Coimbra, 1957, foto.

Variantes: No art. cit. não se dá qualquer interpretação; 1. 2: não se tem em conta a provável existência do $\mathrm{S}$.

Paginação cuidada, com alinhamento à esquerda e à direita. Caracteres esguios, inclinados para um lado ou para outro, de tamanho irregular apesar das linhas auxiliares: barras horizontais curtas, R com a parte superior bastante pequena. Na l. 2, uma mossa fez desaparecer uma letra, possivelmente S. Pontos circulares, somente visíveis no final da 1.2.

Trata-se dum peregrino, cujo gentilício, Naeidius, surge aqui, segundo cremos, pela primeira vez. Deverá estar por Naevidius, que se regista na epigrafia de Collipo $\left({ }^{19}\right)$, como nos sugeriu M. Lourdes Albertos.

Note-se não só a ausência da invocação aos Manes e o uso duma fórmula final sincopada sem H. S. E., como também o emprego do genitivo $(\mathrm{I}=\mathrm{II})$ não muito frequente na epigrafia do sul de Portugal - mas que vamos encontrar também no número seguinte.

Estas características formais sugerem uma datação remota - a primeira metade do séc. I.

\section{$7-$ Foto 7}

Estela funerária em dolomito, poroso, esverdeado, encontrada na freguesia de Casével, Castro Verde. Vagamente fusiforme, contornos irregulares; campo epigráfico alisado, rebaixado, embora de limite bem definido apenas superiormente.

Dimensões: $136 \times 43 \times 10$. Campo epigráfico situado a $44 \mathrm{~cm}$ do vértice superior.

(19) Brandão (D. Pinho), "Conimbriga", XI, 1972, n. ${ }^{\circ} \mathrm{V}(\mathrm{p} .67-70) \mathrm{e}$ n. ${ }^{\circ}$ XIV (p. 96-97). 


\section{$\mathrm{M}($ arci $) \cdot \operatorname{POSTV} / \mathrm{MI} \cdot \mathrm{L}($ ucii $) \cdot \mathrm{F}($ ilii $)$}

De Marcos Postúmio, filho de Lúcio.

Alt. das letras: 1. 1: $7(\mathrm{~T}=8) ; 1.2: \mathrm{M}=6,5 ; \quad \mathrm{I}=7$; $\mathrm{L}=7,5 ; \mathrm{F}=8,3$. Espaços: 1: 0,5/2,5;2: 3,5; 3: 69 (até ao vértice inferior).

Inédita.

Alinhamento à esquerda. Gravação pouco profunda. M largo, $\mathrm{P}$ não fechado, $\mathrm{O}$ bem redondo. Barras horizontais extraordinariamente curtas - a intermédia, do F, colocada acima do meio. Pontos circulares utilizados a rigor.

Texto muito simples, apenas com a identificação sumária do defunto, em genitivo mais uma vez, omitindo-se o cognome, sugere-nos uma data bastante remota - os começos do Império. O gentilício Postúmio, que surge aqui pela primeira vez no conventus Pacensis, encontra-se muito difundido na Península Ibérica.

\section{$8-$ Foto 8}

Fragmento de estela em xisto amarelado, encontrada perto da estação ferroviária de Montenegro, Panóias, Ourique. Apenas se conserva pequena parte do texto, cuja reconstituição se nos afigura difícil, por ter aparentemente uma estrutura fora do habitual. A superficie foi afeiçoada para receber a inscrição, tendo-se mesmo recorrido à execução de linhas auxiliares duplas muito semelhantes às da epigrafe $n .^{0} 6$, visiveis somente no canto superior esquerdo. O texto poderia ter tido mais uma linha em cima, e continuava para a direita, donde saltou uma grande lasca $\left({ }^{20}\right)$.

\footnotetext{
$[\ldots] /[\ldots]$ VIRIAE $[\ldots$ ? $]$ / IVLIA $[\mathrm{M} ? \ldots] / \mathrm{MV}[\ldots] / \mathrm{C}($ aius $)$. $. \mathrm{IV}] \mathrm{L}[\mathrm{I}] \mathrm{VS}$ ? $][\ldots]$
}

Inédita.

$\left({ }^{20}\right)$ Não nos foi possivel obter as dimensões da peça, que está numa casa habitualmente fechada, pertencente à paróquia. 
A gravação fora nítida. Paginação segundo critério indefinivel. Caracteres actuários, esguios, de barras horizontais curtas. A pontuação seria circular.

$\mathrm{Na}$ 1. 1, a lasca da pedra induziria a ler $\mathrm{B}$ (em vez de R); contudo, a observação atenta da parte inferior leva-nos a preferir o gentilício Viria, bem documentado na Península.

O texto referirá diversos defuntos, dois dos quais pertencentes à gens Iulia. Outra hipótese interpretativa, mais provável, será a de considerarmos o nome da defunta em dativo (Viriae), de sorte que os outros dois antropónimos seriam os dos dedicantes.

\section{CONCLUSÃO}

Por conseguinte, se exceptuarmos este último texto, e sem nos querermos lançar numa análise pormenorizada tendo em vista toda a epigrafia da região, parecem-nos de sublinhar alguns traços comuns dos monumentos estudados:

- a identidade do material: utilização dos xistos existentes na região;

- a identidade da tipologia: uso preferencial do tipo estela, relacionável com uma tradição vinda já da Idade do Bronze ${ }^{(21}$ ); decoração inexistente; preparação — rude -- do campo epigráfico; existência de linhas auxiliares;

- uma onomástica indigena recentemente adaptada à onomástica latina, denotando uma população que acaba de sentir os efeitos da romanização. Um cuidado em apontar a filiação, quer o patronímico seja indígena ( $A P$ XIII 1908 p. 283-4, CIL II 98, n. ${ }^{\circ}$ ) quer venha indicado bem à latina só com a sigla do praenomen

${ }^{(21)}$ Existiu mesmo uma Cultura do Bronze do Sudoeste ("Conimbriga» XV, 1976, p. 9); por outro lado, numa estela funerária romana encontrada na região (Peroguarda, Ferreira do Alentejo), cujo paradeiro actual se desconhece mas de que restam desenhos e fotografias, persiste a decoração típica das estelas do Bronze: «Vê-se também um objecto do feitio de um feixe de pequenos rectângulos, semelhante aos que se vêem representados nas tampas das cistas baixo-alentejanas, de tipo argárico, com armas insculturadas» (Abel VIANA, "Arquivo de Beja", XVIII-XIX, 1961-1962, p. 122; cfr. também Abel VIANA, Museu Regional de Évora - Seç̧ão Lapidar, Beja, 1946, p. 79-80). 
(CIL II 76, n. os 4 e 7). De notar, a frequência do gentilício imperial Iulius: 7 exemplos em 12 textos (incluindo os quatro citados na nota 2).

- a concisão dos textos: ausência da invocação aos deuses Manes, omissão frequente de fórmulas funerárias ou utilização de fórmulas sincopadas - o que denotará exactamente a incipiente adopção de hábitos epigráficos alheios. A par da indicação, mais usual, do nome do defunto em nominativo, registe-se a ocorrência do genitivo (CIL II 76, n.os 6 e 7).

Os traços individualizantes detectados epigraficamente terão correspondência histórico-cultural? Ou, por outras palavras, o estrato populacional que, nos começos do Império, habitou o sudoeste alentejano, terá características sócio-económicas e étnicas que o distingam da restante população? (22).

\author{
José D'Encarnação
}

${ }^{(22)}$ As fotografias que ilustram este trabalho-com excepção da n. ${ }^{\circ} 2$ - foram executadas por Guilherme Cardoso, cuja solícita colaboração agradecemos. A foto n. ${ }^{\circ} 2$ foi-nos cedida por Jorge Pinho Monteiro, cuja atenção agradecemos. 
EsT. I

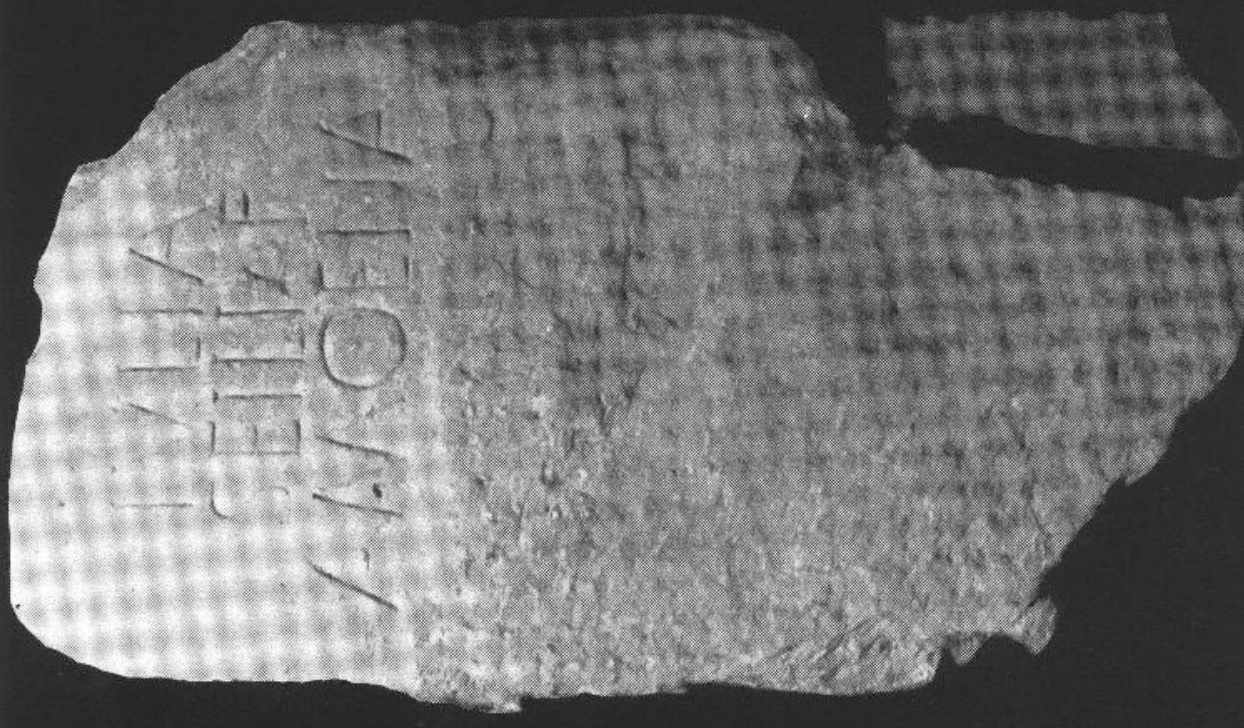

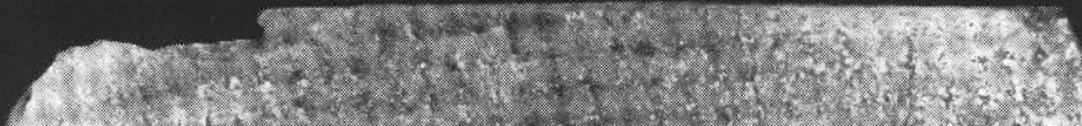

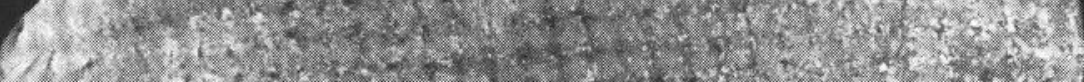

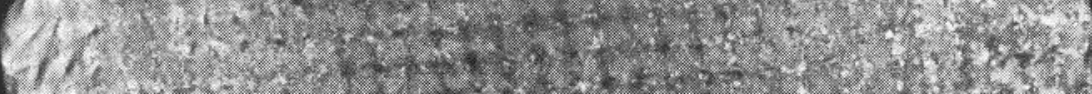

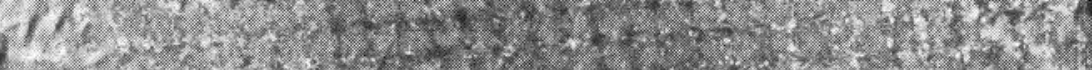

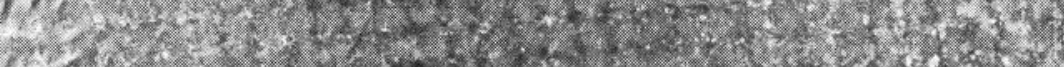
(1.2.

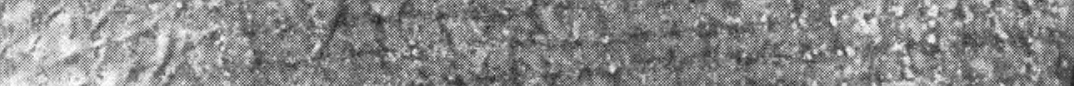

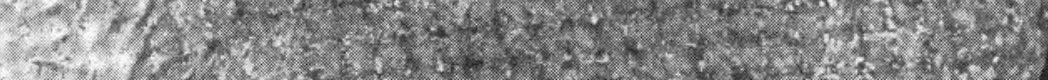

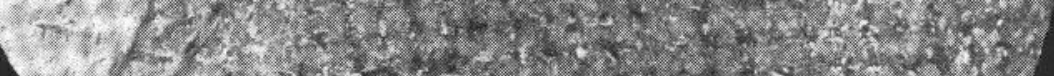

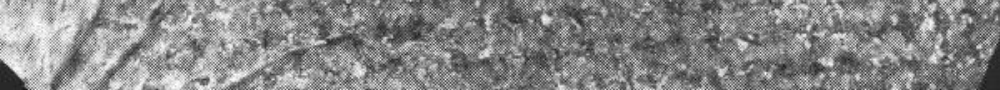

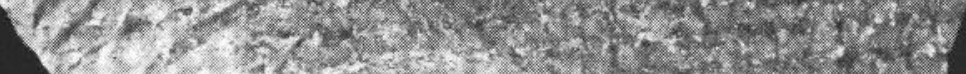

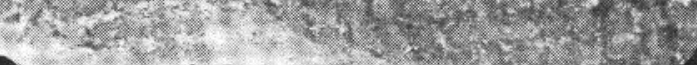


Esт. II

$\omega$

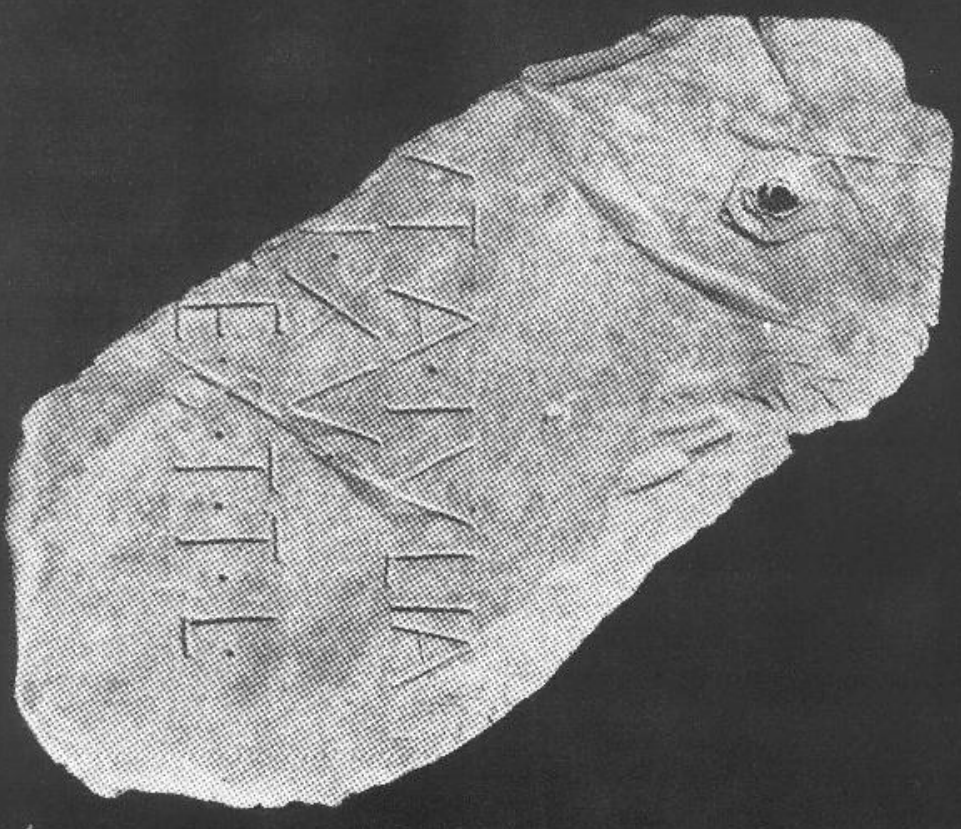

w

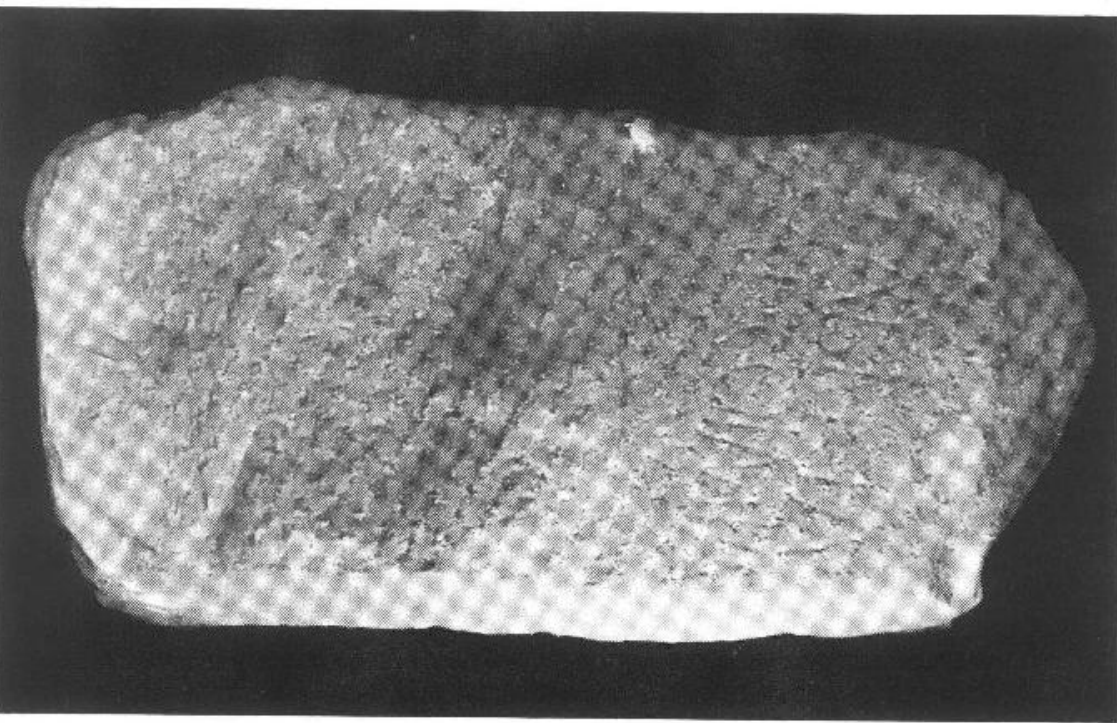



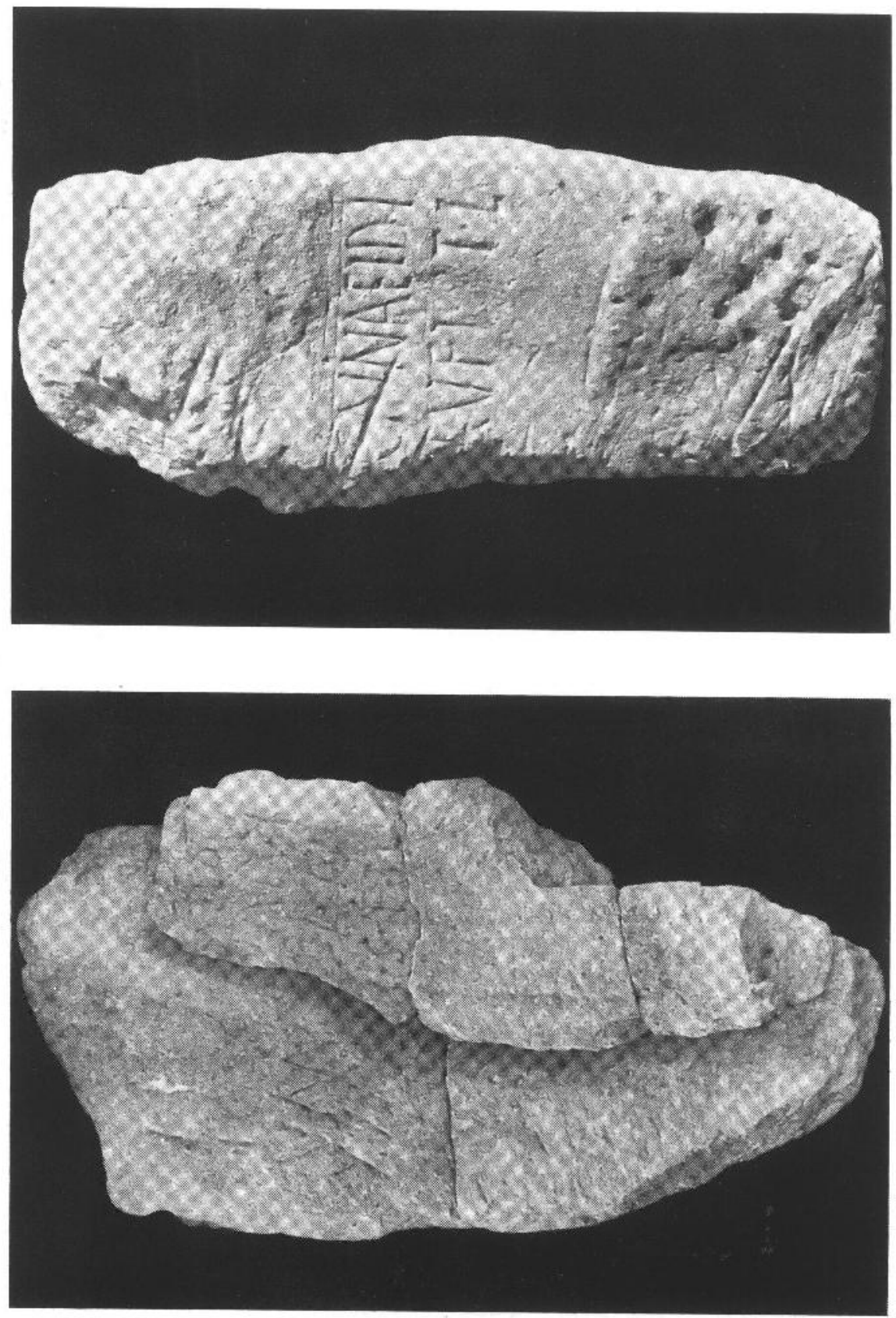
EsT. IV

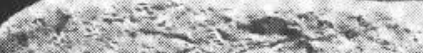
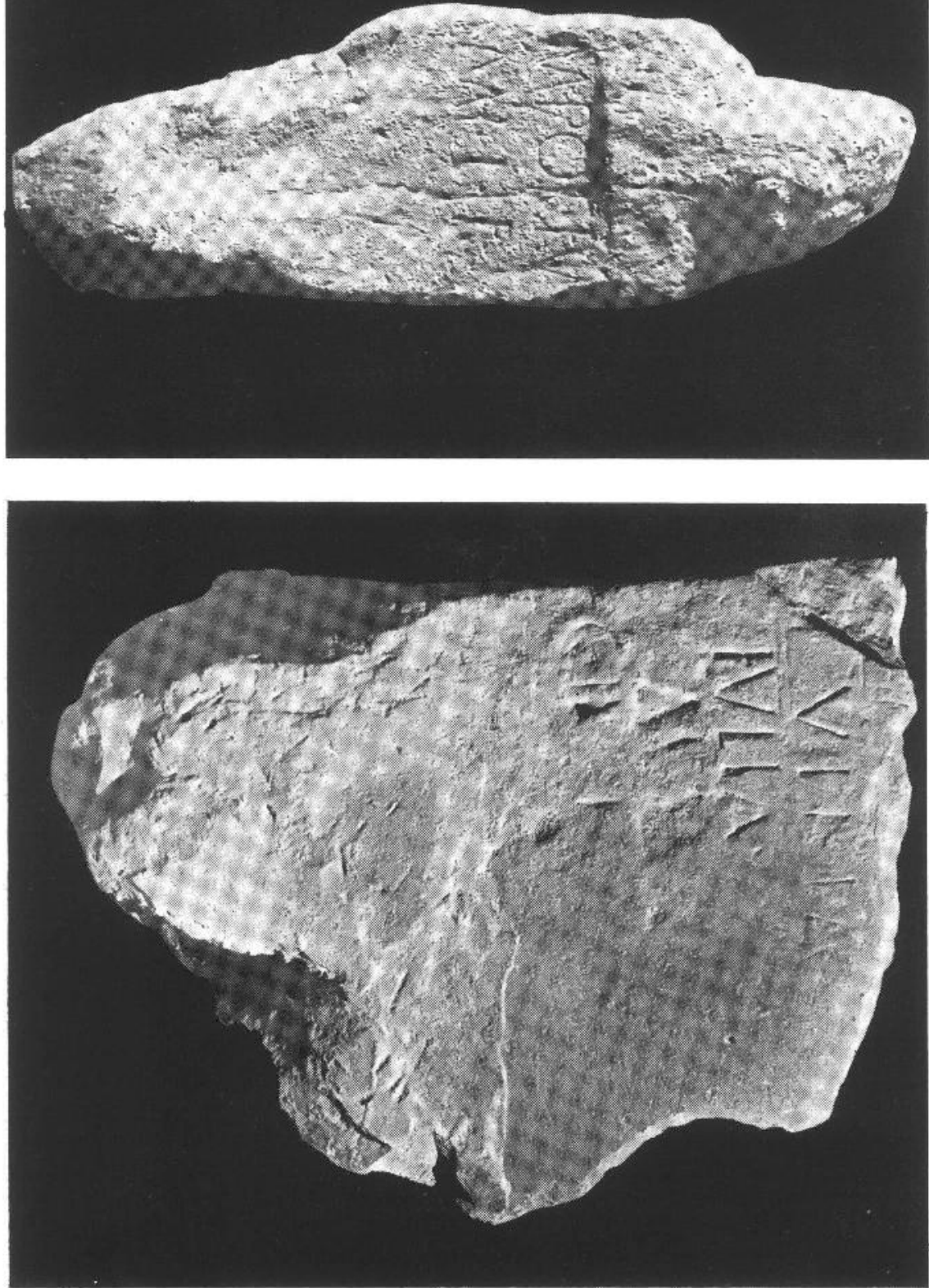